\title{
DESIGN E O PERCURSO FEMINISTA: O COLETIVO GRÁFICO FEMININO DE CHICAGO
}

\section{DESIGN AND THE FEMINIST JOURNEY: CHICAGO WOMEN'S GRAPHIC COLLECTIVE}

\author{
Roberta Coelho Barros ${ }^{1}$ \\ Paula Garcia Lima ${ }^{2}$ \\ Thaís Cristina Martino Sehn ${ }^{3}$
}

\begin{abstract}
Resumo
Este trabalho visa estudar o design gráfico como uma ferramenta de expressão visual que reflete o contexto no qual está inserido. Neste caso, é analisada a força persuasiva dos cartazes do Coletivo Gráfico Feminino de Chicago durante a segunda onda do movimento feminista. Através da análise das peças "Women are not chicks" e "Sisterhood is blooming", a partir de Jolly (1996), busca-se compreender o design enquanto vestígio material que permite observações de outros tempos. Assim, percebe-se a relação entre os elementos gráficos utilizados nos cartazes e os propósitos feministas daquele contexto, que questionavam as divisões de gênero e a desigualdade entre os sexos.
\end{abstract}

Palavras-chave: design gráfico; feminismo; cartaz; Chicago Women's Graphic Collective.

\begin{abstract}
This paper aims to study graphic design as a visual expression tool that reflects the context in which it is inserted. In this case, we analyze the persuasive force of the posters of the Chicago Women's Graphic Collective during the second wave of the feminist movement. Through the analysis of "Women are not chicks" and "Sisterhood is blooming", based on Jolly (1996), we seek to understand design as a material trace that allows observations from other times. Thus, we relate the graphics used on these posters with the feminist purposes of the movement, which questioned gender divisions and gender inequality.
\end{abstract}

Keywords: graphic design; feminism; poster; Chicago Women's Graphic Collective.

\footnotetext{
1 Professora Doutora em Comunicação Social, Colegiado de Design - Centro de Artes - UFPel, robertabarros@gmail.com

2 Professora Doutora em Memória e Patrimônio, Colegiado de Design - Centro de Artes - UFPel, paulaglima@gmail.com

3 Doutoranda em Design, Pós-graduação em Design - PPGDESIGN - UFRGS, crisehn@gmail.com
} 


\section{Introdução}

O design gráfico é uma ferramenta com forte poder de persuasão. Ao longo da história existem diversos momentos que atestam essa característica. Nos anos 1970, o grupo Chicago Women's Graphic Collective (Coletivo Gráfico Feminino de Chicago) fez do uso de cartazes um de seus principais instrumentos para reivindicar os ideais da segunda onda do movimento feminista. A compreensão dos produtos do design gráfico como expressões visuais e conceituais, que emanam e refletem a cultura na qual circulam, é a motivação maior da reflexão proposta através do presente texto. Para além de resultados estéticos, acredita-se na força persuasiva e política (em seu sentido mais amplo) do design. Para a aproximação indicada, tomaram-se como objetos de análise dois cartazes desse Coletivo, "Women are not chicks" (1972) e "Sisterhood is blooming" (1972).

A partir destas vertentes propulsoras, inicia-se a discussão com um percurso histórico do referido movimento, através de autores como Pinto (2010), Piscitelli (2002), Haraway (2004) e Beauvoir (1980); passando-se, a seguir, para a apresentação do Coletivo das mulheres de Chicago, com vistas a contextualizar a discussão e fornecer maiores subsídios para as análises gráficas que acontecem na sequência.

A ferramenta de análise utilizada foi a sugerida por Jolly (1996) em seu livro "Uma introdução à análise de imagem". A escolha desta justifica-se pela proposição de uma observação sistemática entre a relação de três tipos de mensagem: a plástica, a icônica e a linguística.

Este trabalho suscita uma discussão que se volta para objetos gráficos e movimentos pretéritos, demonstrando que, além da associação primeira que motivou o estudo, emerge uma segunda relação: a de peças gráficas enquanto vestígios materiais que permitem observações de outros tempos, trazendo para primeiro plano a relação entre o design gráfico e a cultura material de diferentes épocas. Estes cartazes, assim como diversos outros criados pelo Coletivo ainda na década de 1970, são comercializados até os dias de hoje. Isto mostra a relevância dos valores reivindicados na época e reforça sua pertinência na sociedade contemporânea, pois atualizados dentro de um novo contexto, esses cartazes mostram que apesar das muitas conquistas desse movimento, ainda há muito pelo que lutar.

\section{O Percurso Feminista}

Tendo em vista a proposta de analisar a produção gráfica do grupo Chicago Women's Graphic Collective, que atuou em prol da liberação feminina, considerou-se pertinente realizar uma contextualização histórica concernente ao percurso feminista.

O feminismo é um movimento que já atravessa séculos, tendo sofrido algumas adaptações no que diz respeito aos motivos principais de luta. A autora Céli Pinto (2010), localiza o início da primeira onda feminista ao final do século XIX, mesmo que anteriormente já houvesse ocorrido ao longo da história exemplos de manifestações de mulheres em prol de sua liberdade. Neste século, os pressupostos de "direitos iguais à cidadania", levaram, por conseguinte, à noção de igualdade entre os sexos, desencadeando alguns movimentos de mulheres na Europa, na América do Norte e mais alguns países (PISCITELLI, 2002).

A chamada primeira onda feminista, com grande efervescência pouco antes dos anos 1920 e dos anos 1930, se deu em função de ações de mulheres, inicialmente na Inglaterra, com a reivindicação primeira de direito ao voto e, também, de acesso à propriedade e à educação (PINTO, 2010; PISCITELLI, 2002). As inglesas ficaram conhecidas como suffragettes e ganharam o direito de votar no ano de 1918. 
O movimento feminista perde a força a partir da década de 1930 e somente é retomado na década de 1960. Entre estas décadas o livro de Simone de Beauvoir, "O segundo sexo", foi de fundamental importância para o considerado segundo momento do feminismo, pois foi instrumento teórico de referência para as mulheres, especialmente aquelas que compunham o meio letrado.

Logo, durante o século XX houve uma mudança entre as reivindicações, primeiramente o movimento ganhou força entre as mulheres trabalhadoras e, depois, entre as mulheres dos setores médios. Esta segunda onda, a partir de 1960, tem como cenários importantes e propícios para o seu desenvolvimento, novamente, os Estados Unidos e a Europa. Neste contexto o movimento feminista cresce como um movimento libertário, que passa a questionar de maneira mais direta outra forma de dominação que não a de classe: a do homem sobre a mulher, com ênfase no direito de as mulheres poderem decidir sobre suas próprias vidas e seus próprios corpos, através de reflexões relacionadas ao prazer sexual, direito ao aborto e utilização de métodos contraceptivos. A reivindicação agora não era somente para que as mulheres ocupassem determinados espaços, mas principalmente para que a relação entre homens e mulheres ocorresse de forma diferente (PINTO, 2010).

A subordinação feminina passou a ser entendida como algo universal, recorrente em qualquer contexto geográfico, mas que, no entanto, variava de acordo com o local e a época histórica. Entendia-se que tal subordinação era uma decorrência da construção social da mulher e que, logo, poderia ser transformada. É sobre a ideia de opressão disseminada em todos os contextos que, segundo Franchetto et al. (1981), repousa a compreensão de universalidade da categoria mulher, no fato de que a identidade de todas as mulheres seria advinda da sua natureza fisiológica. Foi neste aspecto que as feministas do período concentraram os seus esforços, mesmo com divergências em relação às origens e causas da opressão feminina. Destaca-se que, nesta década, Estados Unidos e Europa tinham como pano de fundo inúmeros movimentos libertários, atingindo o ápice com os movimentos estudantis de 1968, situação propícia para que o movimento ganhasse espaço.

Foi no momento do pós-guerra e das reivindicações feministas da segunda onda que surgiu o conceito de gênero, em 1963, por Robert Stoller, o qual atingiu maior alcance a partir de Gayle Rubin, em 1975, com o trabalho de grande vulto para área, "The Traffic in Women", onde a autora alcunhou a expressão sistema sexo/gênero (NICHOLSON, 2000; SAFFIOTI, 1999). Stoller, tendo como foco as identidades de gênero fez a distinção entre biologia e cultura e, por sua vez, diferenciou sexo de gênero, tendo em vista que atrelou sexo à biologia e gênero à cultura (HARAWAY, 2004).

Sobre a formulação do conceito, Haraway (2004, p.211) traz a importância fundamental do trabalho de Simone de Beauvoir que, conforme já citado, alimentou teoricamente as feministas que deram origem à segunda onda, pois, segundo a autora, mesmo com algumas diferenças, todos os significados modernos de gênero estão focados na afirmação de Beauvoir de que "ninguém nasce mulher: torna-se mulher" (BEAUVOIR, 1967, p.9). A referida frase da autora inicia o segundo volume da sua obra, o que parece ser, portanto, uma constatação feita após o questionamento do que é ser uma mulher, que ela pauta no início do seu primeiro volume (BEAUVOIR, 1980). A autora comenta que nominar é uma necessidade humana e que declarar ser mulher é uma necessidade identitária feminina, enquanto ser homem seria algo natural, logo, sem necessidade de exaltação. Neste sentido, ela segue explanando que o homem é considerado o absoluto, enquanto a mulher é configurada como o Outro (Idem, p.8-11).

Foi com este cenário social e teórico que o conceito de gênero, dentro do feminismo, 
então, foi formulado, objetivando contrapor a naturalização das diferenças sexuais nas mais diferentes áreas. Para Haraway $(2004$, p.211), tanto a teoria quanto a prática feminista em torno do gênero "buscam explicar e transformar sistemas históricos de diferença sexual nos quais 'homens' e 'mulheres' são socialmente constituídos e posicionados em relações de hierarquia e antagonismo".

A universalidade da opressão feminina, bem como a universalidade da categoria mulher, estiveram presentes nas discussões feministas da segunda onda, através dos contrapontos entre os chamados "determinismos biológicos" e "construcionismo social". A binária diferença proposta por Stoller entre sexo e gênero não foi combatida pelas feministas do período, pois mesmo que sugerisse identidades de gênero essencializadas para cada um dos sexos, esta diferenciação era útil para combater a ideia de determinismo biológico, embasando a defesa, então, de gênero como uma construção social (HARAWAY, 2004, p.217218).

É neste contexto da segunda onda, com as preocupações e ponderações apresentadas, que se insere o grupo Chicago Women's Graphic Collective, cuja produção gráfica, a serviço dos ideais feministas do período, neste texto, se propõe analisar.

\section{Coletivo Gráfico Feminino de Chicago}

Segundo o site do Coletivo (CHICAGO, 2004), o grupo surgiu em Chicago, nos EUA - país de grande força no surgimento e exercício do feminismo, como visto anteriormente. Este Coletivo, fundado em 1970 como um comitê artístico ou "grupo de trabalho" pertencente à União de Liberação das Mulheres de Chicago (Chicago Women's Liberation Union), tinha como objetivo criar cartazes para o crescente movimento de liberação feminina (STACY, 2004). Suas fundadoras (Estelle Carol, Tibby L., Helene M., Candida H., Barbara C. e Valerie W.) queriam que sua nova arte feminista fosse um processo coletivo, de forma a separá-la da cultura artística dominada pelos homens ocidentais, por isso, reuniram mulheres interessadas em promover a agenda do movimento de liberação feminina e outras causas políticas e sociais, sem ter, necessariamente, uma formação acadêmica. Elas acreditavam que o design gráfico poderia ser uma voz vital e revolucionária dentro do movimento, sem necessitar de padrões estilísticos. Sua intenção era produzir cartazes para divulgar eventos e questões importantes, assim como, dar às mulheres uma oportunidade para descobrir seu próprio potencial através da experiência compartilhada da criação artística. O Coletivo não queria ser limitado a apenas alguns artistas e, sim, aberto a "todas as nossas irmãs", comenta Carol, pois mesmo com a necessidade de algum treinamento prático, qualquer um que quisesse contribuir poderia participar. A seguir, uma fotografia do grupo, em 1972 (Figura 1).

O grupo utilizava a serigrafia como técnica de impressão, o que permitia a distribuição de peças originais em grandes formatos, em grande quantidade, atingindo um vasto número de pessoas com baixo custo, já que dispunham de um orçamento pequeno. Cada cartaz era criado por um comitê de duas a quatro mulheres, lideradas por uma artista/designer. 0 Coletivo acreditava que o grupo poderia suprir a necessidade, tanto de trabalhos femininos de alta qualidade gráfica, quanto de identificação entre as mulheres artistas, já que através do grupo elas tinham a oportunidade de apoiar umas às outras e também de combinar recursos para um trabalho com maior variedade de materiais e equipamentos do que cada uma disporia individualmente. Segundo uma declaração pública do Coletivo, pertencer ao grupo fazia com que a identificação com o movimento feminino se tornasse mais real; para elas, uma Imagem visual comunica às pessoas e expressa o tom de um movimento de forma especial, que não pode ser substituído por palavras. 
Figura 1: Coletivo Gráfico Feminino de Chicago, 1972

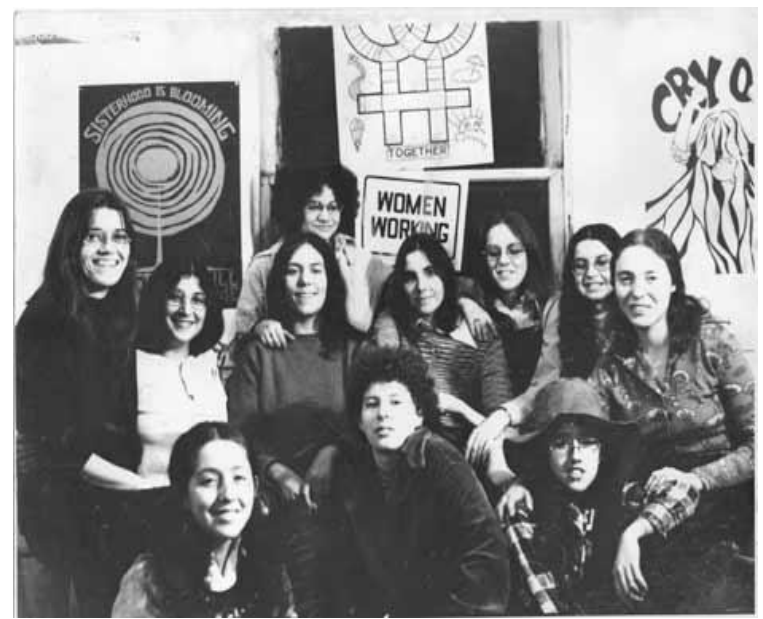

Fonte: http://www.uic.edu/orgs/cwluherstory/CWLUGallery/graphcoll.html

O Chicago Women's Graphic Collective, que inicialmente tinha uma função auxiliar em relação à liberação feminina, pois "servia" a todos os grupos de liberação sem existir como organização política em separado, assumiu uma maior responsabilidade dentro do movimento ao operar como organização autônoma. As peças produzidas, que até então eram destinadas a promover eventos culturais e despertar o nível de consciência das mulheres não envolvidas com grupos de liberação feminina, tornaram-se formas viáveis de comunicação entre mulheres liberacionistas, não-liberacionistas e artistas. Desta forma, as mulheres que não queriam contribuir para organizações feministas radicais puderam contribuir com um movimento feminino mais amplo, sem separar suas identidades como artistas e revolucionárias. Seu papel era comunicar através de peças gráficas os objetivos do movimento de liberação feminina. Ao organizar-se como um Coletivo de todas as mulheres, elas atacaram a visão tradicional da comunicação visual da época, como um domínio exclusivo dos homens.

A estrutura e os membros do Coletivo nunca foram permanentes, mantendo-se em constante estado de transição. O número de membros oscilava entre cinco e 25 mulheres, que trabalhavam como artistas do comitê ou voluntárias por ocasião. Não-membros frequentemente ajudavam com o processo físico da impressão, dependendo do número de cartazes que o Coletivo precisava produzir. A estrutura organizacional do grupo foi fundamental para seu ímpeto e força dentro do movimento de liberação feminina. Milhares de cartazes foram vendidos ao redor do mundo até a dissolução do Coletivo, em 1983.

\section{Análise}

Para fazer a análise dos cartazes optou-se por seguir os preceitos de Martine Jolly (1996), tendo em vista que essas peças se encaixam como mensagens visuais, fixas e heterogêneas. A análise se dá a partir de uma observação sistemática entre a relação de três tipos de mensagem: a plástica, a icônica e a linguística.

Jolly (1996, p. 92) define os elementos plásticos como "signos plenos e inteiros e não simples material de expressão dos signos icônicos (figurativos)"; compreendendo as cores, formas, composição e textura. A mensagem icônica destaca as conotações de segundo nível da imagem descrita na mensagem plástica, contudo algumas significações da mensagem não estão contidas unicamente nos signos icônicos. Por fim, também são avaliados os signos 
linguísticos, ou seja, a mensagem textual que acompanha a imagem tem o poder de validar ou invalidar a mesma, indicando o "nível correto" de leitura da figura.

Foram selecionados dois cartazes para serem analisados, "Women are not chicks" e "Sisterhood is blooming". Em função de existir um acervo muito rico e com diferentes estilos gráficos, para esta escolha optou-se por selecionar aqueles que estavam em destaque na área do site4 para venda dos materiais do coletivo, supondo que estes seriam os mais representativos para o grupo por estarem localizados numa área que visa atingir o consumidor em potencial (Figura 2). O objetivo da produção desses cartazes era a divulgação de seus ideais, através da publicação e venda dos mesmos. Hoje em dia, além dos pôsteres, são oferecidos outros produtos, como camisetas, ímãs etc. $O$ dinheiro arrecadado é destinado ao próprio projeto CWLU Herstory Project.

Figura 2: Captura de tela da página de abertura da loja virtual CWLU Herstory Project na data 7 de maio de 2016.

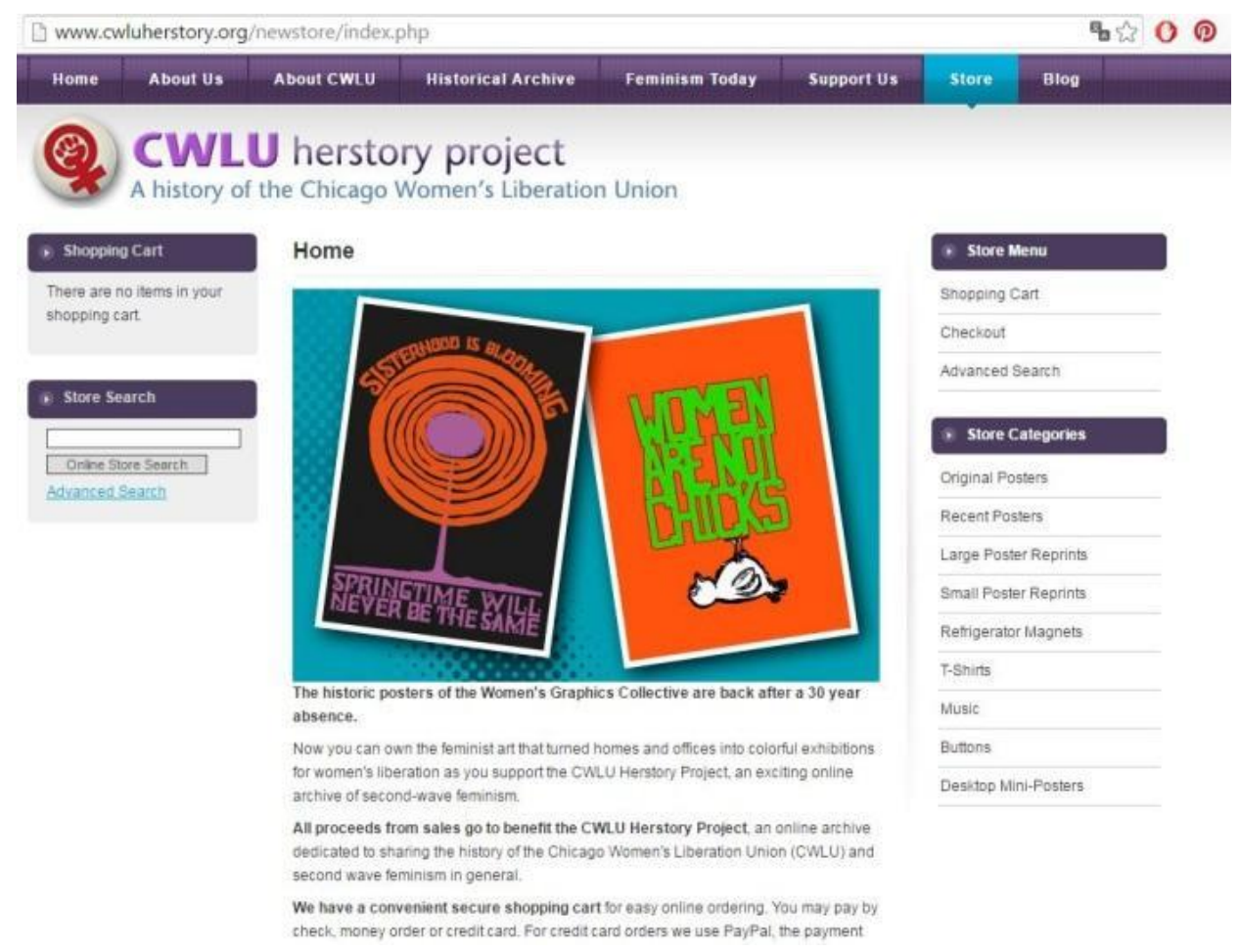

Fonte: www.cwluherstory.org/newstore/index.php

\subsection{Women Are Not Chicks}

O cartaz "Women are not chicks" (Figura 3), que em português pode ser traduzido como "Mulheres não são franguinhos/covardes", foi criado em 1972 e impresso através da técnica de serigrafia, com medidas em torno de $100 \times 70 \mathrm{~cm}$, embora não se possa precisá-las, por falta de dados. 
Figura 3: Women are not chicks. Chicago Graphic Collective, 1972

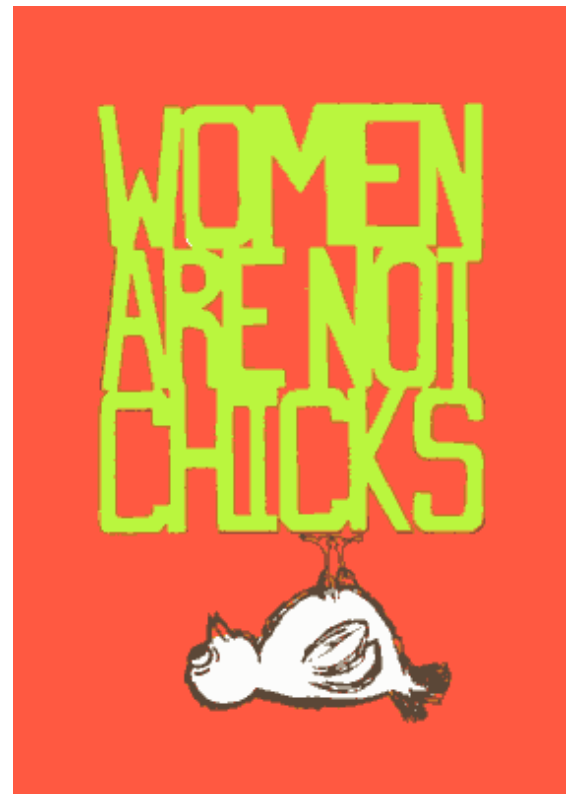

Fonte: http://www.uic.edu/orgs/cwluherstory/CWLUGallery/notchicks.html

Os elementos plásticos se misturam com os linguísticos, pois estes últimos possuem grande destaque no cartaz, tornando a imagem uma complementação do texto, enfatizando o que já está informado verbalmente. Visualmente, destaca-se o bloco de texto na cor verde, sobre um fundo liso de cor laranja, com a mensagem central, "Women are not chicks"; e a figura representando o dito "franguinho" aparece de cabeça para baixo, como se apoiada neste bloco de texto.

Existe um grande contraste entre as cores principais, o laranja do fundo e o verde do texto, pois são cores complementares, ou seja, aquelas que se encontram diametralmente opostas no espectro, o que ocasiona um maior contraste visual entre elas. $\mathrm{O}$ uso reduzido das cores (laranja, verde, preto e branco), além de tornar o cartaz mais objetivo, pode ser atribuído ao tipo de impressão utilizado pelo movimento - a serigrafia - na qual cada cor deve ser impressa separadamente.

A tipografia utilizada para a escrita é reta e espessa, e embora não aparente ser manuscrita, também não revela um padrão que se mostre rígido ou formal. As letras, em caixa alta, formam blocos na cor verde que se intersectam lado a lado e a cada linha, onde estas se encontram. Uma sombra de cor preta é utilizada por trás do texto para facilitar sua leitura, quase como um contorno, dando alguma profundidade ao bloco tipográfico. Este bloco é composto por três linhas, de maneira que o texto apresenta a mesma largura em todas elas e forma um só volume, centralizado verticalmente na peça.

Como elemento icônico pode-se destacar o único elemento figurativo presente na peça, que é o desenho do animal, o franguinho (chick), mencionado no texto. Como uma forma de reforçar a ideia verbal, a ilustração traz também um tom de humor ao cartaz. 0 franguinho, branco, com patas e bico na cor laranja, tem todo o contorno em preto, com traços rabiscados e sobrepostos, claramente feitos à mão, reforçando a ideia de algo desenhado, sem nenhuma intenção de parecer realista.

O tom de humor aparece não só através dos traços manuais, quase displicentes, como também na expressão da figura, com os olhos arregalados, como se mostrando sua inocência 
em relação à apropriação do seu nome, ou mesmo um choque por ter sua figura relacionada com as mulheres de forma negativa. Sua posição, de cabeça para baixo em relação ao texto, também reforça essa ideia de oposição, de não-pertencimento. As mulheres não são franguinhos, e o próprio franguinho está ali retratado para enfatizar essa ideia.

A mensagem relacionada à questão política é compartilhada por um grupo feminista destinada à sociedade em geral e, principalmente, àqueles que não compartilham desta mesma visão, ou seja, é uma imagem que contesta um preconceito vigente e afirma a sua verdade, com a intenção de que esta seja aceita pela sociedade.

\subsection{Sisterhood is Blooming}

A segunda peça gráfica analisada é o cartaz "Sisterhood is blooming" (Figura 4), criado em 1972 e impresso em serigrafia, com medidas de 67x51cm (LIBRARY,1994).

Figura 4: Sisterhood is blooming. Chicago Graphic Collective, 1972

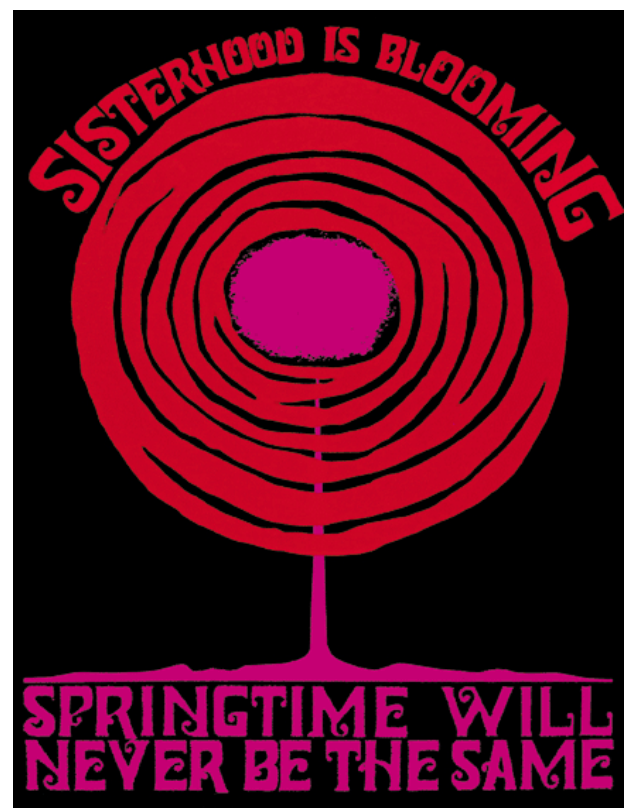

Fonte: http://www.uic.edu/orgs/cwluherstory/CWLUGallery/sister.html

Neste cartaz, novamente há grande relação entre os elementos linguísticos e plásticos, contudo dessa vez, é o elemento plástico que recebe a maior área de destaque no cartaz. A mensagem plástica do cartaz traz elementos com características manuais, pois possuem contornos irregulares, como se tivessem sido desenhados ou recortados, seguindo a linha de muitos cartazes psicodélicos, em voga no momento (MEGGS; PURVIS, 2009). No centro óptico do cartaz há um circulo vermelho, com linhas curvas pretas na parte interna (como se o vermelho fosse vazado e deixasse transparecer o fundo do cartaz). Acima do círculo está escrito o título do cartaz, o texto acompanha a forma curva do círculo. No interior do círculo vermelho há uma forma oval com contorno irregular rosa pink. Por trás do círculo vermelho "desce" uma linha irregular que liga o centro a uma linha horizontal da mesma cor, acima do texto da base do cartaz (Springtime will never be the same).

São utilizadas três cores chapadas no cartaz, preto, vermelho e rosa pink. O preto é 
utilizado no fundo conferindo destaque para os outros elementos, de modo a garantir um bom contraste entre fundo e imagem. Novamente, vale a lembrança do método de impressão na escolha das cores, já que a serigrafia otimiza o uso de tons chapados e sua produção é facilitada com o uso reduzido de número de cores.

A tipografia mantém um padrão ornamental, no qual as extremidades de cada letra possuem curvas orgânicas, que remetem a folhas. Elas possuem uma espessura grossa e a construção de cada letra parece ter sido inserida em retângulo. A cor do texto repete a cor do elemento mais próximo, o superior é vermelho e o inferior é rosa pink.

A mensagem linguística indica a interpretação dos elementos não-verbais. $O$ texto pode ser traduzido como: "A irmandade de mulheres está florescendo: o tempo de primavera nunca mais será o mesmo". Assim, os elementos icônicos podem ser interpretados como uma grande flor, onde o miolo rosa pink lembra uma textura de pólen, o círculo vermelho seria as pétalas e a linha rosa, vertical e horizontal, seria o caule e o solo. Essa flor também pode ser compreendida como um útero - representando a classe feminina - que ganha força com a organização da segunda onda do movimento feminista, relacionando com o título "A irmandade das mulheres está florescendo".

Diferente do cartaz anterior, não é utilizado o recurso do humor, neste a mensagem é mais séria e subjetiva, como se fosse um aviso e uma apresentação do grupo. O Coletivo se apresenta através deste cartaz e enfatiza que as coisas não serão mais iguais, com o trecho "A primavera nunca mais será a mesma", o que pode soar como um prenúncio. A palavra primavera pode ser associada tanto com um período específico do ano quanto com a mulher, pois é a estação em que a natureza floresce, ou seja, a estação das flores, que, por sua vez, também costuma ser relacionada com o feminino. Logo, não apenas os tempos estão mudando como as mulheres estão se transformando, e o Chicago Women's Graphic Collective faz parte dessa transformação.

\section{Considerações Finais}

Pensar no movimento feminista, através do seu percurso histórico, até chegar à sua chamada segunda onda - período coincidente com o surgimento do grupo Chicago Women's Graphic Collective - foi elucidativo para a compreensão das peças gráficas produzidas por este grupo de mulheres. Através da análise das peças, viu-se que, de fato, o grupo alinhava-se com os propósitos feministas daquele contexto, que questionavam as divisões de gênero e a desigualdade entre os sexos. Ao imprimir no cartaz "Women are not chicks", utilizando um franguinho bem humorado para representar isso, elas queriam gritar que não, mulheres não são seres frágeis, tal qual a referida ave, caracterização típica das divisões binárias de gênero (homens fortes, mulheres frágeis, apenas citando um exemplo). Já no cartaz "Sisterhood is blooming", a mensagem enaltece o próprio movimento que está se organizando com a esperança de alterar os dogmas vigentes. A mensagem é passada de forma subjetiva através de metáforas e com forte apelo gráfico, no qual os elementos plásticos reforçam a mensagem textual.

A respeito dos elementos visuais que compõem estes cartazes, já descritos previamente, percebe-se o uso de traços manuais e descontraídos que, em contraponto, transmitem uma mensagem séria. Os anos 1970 foram marcados pela contracultura, período em que as pessoas passaram a demonstrar suas insatisfações em relação à sociedade e a oporse ao sistema, também através do design gráfico. O Chicago Women's Graphic Collective é um exemplo de manifestação através de imagens, a favor de uma causa, neste caso, o movimento feminista. As peças gráficas criadas pelo Coletivo, incluindo os cartazes aqui analisados, tinham 
como objetivo levar sua mensagem ao público, de forma que esta fosse compreendida e, também, adotada. Pode-se afirmar, desta forma, que a mensagem transmitida pela peça tinha uma função persuasiva.

Naquele momento em que as mulheres passaram a questionar a dominação masculina, focando nos seus direitos de tomarem decisões sobre suas vidas e seus corpos, o material gráfico produzido pelo grupo foi uma ferramenta para dar maior visibilidade para as suas reivindicações, sendo que a própria feitura dos mesmos, em oficinas gráficas, por si, já representa um enfrentamento perante as estipulações de gênero. Além disso, como bem disse Simone de Beauvoir "ninguém nasce mulher: torna-se mulher"; tratando-se, portanto, de uma construção que é cultural e social, tal como defendiam as feministas do período. Assim, este ideal de mulheres poderia ser transformado a partir de outro ideal de construção, o da liberdade e da não-opressão. E foi exatamente isto que as mulheres do grupo de Chicago realizaram, pois as peças gráficas são produtos que circulam e permeiam a cultura. Desta forma, elas usaram o resultado de seu trabalho para desconstruir determinadas naturalizações do que era considerado o "ser mulher" naquele cenário. Assim, neste texto, buscou-se apontar a relação entre design e contexto social, em específico, com as reivindicações feministas do período. Propõe-se a continuidade do estudo, de forma a averiguar essas relações em outros momentos importantes da história da mulher dentro do desenvolvimento da sociedade contemporânea.

\section{Referências}

BEAUVOIR, Simone. O Segundo Sexo: a experiência vivida; tradução de Sérgio Millet. 2 ed. São Paulo: Difusão Européia do Livro, 1967.

BEAUVOIR, Simone. O segundo sexo: Fatos e Mitos; tradução de Sérgio Milliet. Rio de Janeiro: Nova Fronteira, 1980.

CHICAGO Women's Graphics Collective. In: CWLU Herstory. 2004. Disponível em: http://www.uic.edu/orgs/cwluherstory/CWLUGallery/graphcoll.html. Acesso em 02/05/2016

FRANCHETTO, Bruna; CAVALCANTI, Maria Laura V. C. e HEILLBORN, Maria Luiza. Antropologia e Feminismo: Perspectivas Antropológicas da Mulher. Rio de Janeiro: Zahar Editores, 1981.

HARAWAY, Donna. "Gênero" para um dicionário marxista: a política sexual de uma palavra. Cadernos Pagu, Campinas, v.22, p.201-246, 2004. Disponível em <http://www.scielo.br/pdf/cpa/n22/n22a09.pdf>. Acesso em: 20 out. 2014.

JOLY, Martine. Introdução à análise da imagem. Campinas: Papirus, 1996

LIBRARY of Congress, Prints \& Photographs Division, [reproduction number, e.g., LC-USZ62103756 (b\&w film copy neg.)]. 1994. Disponível em: http://www.loc.gov/pictures/item/yan1996000796/PP/ Acesso em 04/05/2016

MAYORGA, Claudia; COURA, Alba; MIRALLES, Nerea e CUNHA, Vivane Martins. As críticas ao gênero e a pluralização do feminismo: colonialismo, racismo e política heterossexual. In:

Revista Estudos Feministas, Florianópolis, v.21, n.2, p.463-484, mai./ago. 2013. Disponível em: $<$ http://www.scielo.br/scielo.php?script=sci_arttext\&pid=S0104026X2013000200003\&lng=pt\&nrm= iso >. Acesso em: 05 nov. 2014.

MEGGS, Philip B.; PURVIS, Alston W. História do Design Gráfico. São Paulo: Cosac Naify, 2009 
NICHOLSON, Linda. Interpretando o gênero In: Revista Estudos Feministas, Florianópolis, v. 8, n.2, p.9-42, 2000. Disponível em:

<https://periodicos.ufsc.br/index.php/ref/article/view/11917>. Acesso em: 22 ago. 2014.

PINTO, Céli Regina Jardim. Feminismo, história e poder. In: Rev. Sociol. Polit. , Curitiba, v.18, n.36, p.15-23, jun. 2010. Disponível em:

<http://www.scielo.br/scielo.php?script=sci_arttext\&pid=S0104-44782010000200003 \&lng =pt\&nrm=iso>. Acesso em: 12 ago. 2014

PISCITELLI, A. G. Re-criando a categoria mulher? In: Algranti, Leila Mezan. (Org.). A prática feminista e o conceito de gênero. Campinas: IFCH/UNICAMP, v. 48, p. 7-42, 2002. Arquivo digital, s.p... Acesso em: 26 nov. 2014.

RUBIN, Gayle. O trafico de mulheres: notas sobre a "economia politica" do sexo. Recife: SOS Corpo, 1993.

SAFFIOTI, Heleieth I.B. Primórdios do conceito de gênero. In: Cadernos pagu, Campinas, v.12, p. 157-163, 1999. Disponível em <http://www.Bibliothecadigital.unicamp.br/document/?down=51300>. Acesso em: 10 set. 2014.

STACY, S. .The Chicago Women's Graphics Collective: An Introduction. In: CLW Cluehertory, 2004. Diponível em https://www.uic.edu/orgs/cwluherstory/CWLUGallery/Silver.html. Acesso em 02/03/2016 